\title{
Ethnic tolerance in urban Malaysia
}

\begin{abstract}
This article is aimed at examining the level of ethnic tolerance in Malaysia, with specific reference to the Johor Bahru and Shah Alam parliamentary. It also aimed at identifying the significance difference of ethnic tolerance in research areas. Using quantitative approach with self-administered set of questionnaire, 434 respondents were involved in this study. The result showed that the people of Johor Bahru are more tolerant than Shah Alam. Both Johor Bahru and Shah Alam can be categorized as having a medium level of ethnic tolerance as attitude and perceptions are more important than the issues of party politics and ethnicity. It also concluded that urban voters of mixed majority constituencies are not bounds with ethnicity and racial issue as they used to previously. It is hoped that this particular study contributed to the current body of knowledge. It is significant where ethnic politics perceived as most important matter, and tolerance has become increasingly Malaysia national agenda in managing multi-diversity society. Implications of findings and recommendations are further discussed.
\end{abstract}

Keyword: Ethnic tolerance; Moderate; Urbanism; Voting behaviour 